\title{
Ausencia y presencia estatal como forma de reproducción de la violencia urbana en el distrito de Aguablanca (Cali, Colombia)*
}

DOI: https://doi.org/10.18046/recs.i32.3910

\section{Absence and Presence of the State as a Reproduction Way of Urban Violence in the Aguablanca District (Cali, Colombia)}

\author{
Carlos Andrés Arana-Castañeda**
}

Fundación Academia de Dibujo Profesional (Cali, Colombia)

\footnotetext{
* Este artículo de investigación se deriva de los procesos realizados durante la maestría en Estudios Sociales y Políticos de la Universidad Icesi (Colombia), y del permanente apoyo de lideresas y líderes comunitarios del distrito de Aguablanca. Se financió con recursos propios. Artículo de investigación recibido el 21.02.20 y aceptado el 17.08.2020.

${ }^{* *}$ Magíster en Estudios Sociales y Políticos de la Universidad Icesi (Colombia). Docente investigador y líder de Apropiación Social del Conocimiento, Fundación Academia de Dibujo Profesional (Colombia).Correo electrónico: carlos.arana132@ gmail.com ORCID: https://orcid.org/oooo-0002-0592-9172
} 


\section{Cómo citar/How to cite}

Arana-Castañeda, Carlos Andrés (2020). Ausencia y presencia estatal como forma de reproducción de la violencia urbana en el distrito de Aguablanca (Cali, Colombia). Revista CS, 32, 77-102. https://doi.org/10.18046/recs.i32.3910 


\section{Resumen}

El artículo muestra, a partir de un acercamiento etnográfico, cómo en el distrito de Aguablanca (Cali, Colombia) se manifiestan, simultáneamente, las nociones de presencia y ausencia del Estado, lo cual, en un contexto de violencia urbana, dificulta el reconocimiento de los efectos de sus acciones y omisiones. Al mismo tiempo, se muestra cómo las lecturas sobre la violencia que tienen como propósito generar alternativas para mitigar este flagelo dan paso a la confrontación de los imaginarios de comunidades de zonas marginadas, zonas de élite y el Estado. Aquí emergen prácticas y discursos de señalización que asignan a las comunidades negras y al distrito de Aguablanca identidades violentas, que sirven para mostrarlos como los responsables de que Cali sea una de las ciudades más violentas del mundo, lo que a su vez favorece la ejecución de prácticas de segregación racial y territorial, y acciones estatales y paraestatales que reproducen violencia.

PALABRAS CLAVE:

Estado, ausencia, presencia, violencia, distrito de Aguablanca

Based on an ethnographic approach, this article describes how the notions of presence and absence of the state are manifested, simultaneously, in the Aguablanca District (Cali, Colombia). Within a context of urban violence, this is an obstacle when recognizing the effects of the state's actions and omissions. Additionally, it can be noticed how the readings on violence intending to generate alternatives to mitigate this scourge enable the confrontation of imaginaries between communities from marginalized areas, elite areas, and the state. Thus, we see the emergence of signaling practices and discourses that assign violent identities to black communities and the Aguablanca District, which serve to present them as accountable for Cali being one of the most violent cities in the world, and it favors the execution of racial and territorial segregation practices, and "state" and "parastatal" actions that reproduce violence.

\section{KEYWORDS:}

State, Absence, Presence, Violence, Aguablanca District 



\section{Introducción}

Microtráfico, fronteras invisibles y la acción de pandillas suelen ser presentados como factores relacionados con los altos índices de homicidio que se registran en zonas urbanas marginadas. Esto genera la circulación de discursos e imaginarios donde, como una explicación, se aduce que esta realidad se debe a las acciones que se gestan en la ausencia del Estado y, en otros casos, a su acción violenta. La presencia y ausencia estatal, que llegan incluso a manifestarse simultáneamente para la explicación de un hecho violento, generan ambigüedades respecto a lo que pueden significar en un contexto de violencia urbana la seguridad, el orden y la justicia, por lo cual es necesario analizar la manera como esta paradoja influye sobre las dinámicas de violencia urbana. Por eso, el artículo muestra cómo en zonas urbanas marginadas, como el distrito de Aguablanca (Cali, Colombia), la presencia y ausencia simultánea del Estado configura órdenes sociales en las que el efecto de los imaginarios racializados llevan a que se reconozcan prácticas estatales y paraestatales que reproducen violencia.

En este sentido, priorizar las manifestaciones y experiencias comunitarias sobre las del Estado-o viceversa-para explicar la violencia resulta insuficiente. Asimismo, responsabilizar solo al Estado o a las pandillas por establecer un orden que culpabiliza a una comunidad mientras victimiza a otra es, de cierta manera, una mirada reduccionista. Por lo tanto, para comprender el papel que el Estado (ausente o presente) ocupa en la confrontación o reproducción de la violencia, será importante conectar los relatos etnográficos de la comunidad del distrito de Aguablanca con los de otros sectores de la ciudad, y las manifestaciones estatales que, como veremos, permitirá avanzar en formas de interpretación de la violencia a partir de la integración de aspectos cualitativos y cuantitativos (Cabrera, 2018).

Se realizó pues un acercamiento etnográfico que permitió, por medio de la observación participante y entrevistas entre 2017 y 2019, registrar las experiencias y reflexiones de jóvenes y madres del distrito de Aguablanca sobre la violencia, sus efectos y actores; estas tuvieron lugar en talleres (semanales) con un grupo juvenil, mesas de trabajo con madres cuyos hijos fueron asesinados, y encuentros convocados por organizaciones no gubernamentales (ONG). También se incluyen conversaciones personales con comerciantes y habitantes de otras zonas de la ciudad. El artículo se divide en tres secciones: inicia con una breve presentación de cómo

1. Los nombres de las personas fueron omitidos para conservar la integridad de los habitantes del distrito de Aguablanca, por lo que, en ocasiones, se presentan frases de jóvenes, madres o comerciantes sin especificar su origen. Los nombres de los lugares se mantienen para una referencia cercana del sitio de realización del trabajo. 
se manifiestan simultáneamente la presencia y ausencia del Estado en el distrito de Aguablanca; después se muestra cuáles son los imaginarios sociales que, como efecto de la ausencia y presencia del Estado, racializan la violencia; y, por último, se describe cómo esta paradoja da paso a acciones de funcionarios o instituciones del Estado que reproducen violencia.

\section{Presencia y ausencia del Estado}

A mediados del siglo XX, el distrito de Aguablanca, ubicado en el oriente de Cali y conformado por las comunas 13, 14, 15 y 21, se caracterizó por ser un sector donde el asentamiento de la población y el avance de infraestructura se logró -mayoritariamente-a partir de las prácticas de autogestión de mujeres y hombres negros que huyeron de la violencia que azotaba la región del Pacífico colombiano o llegaron a Cali en busca de la ciudad prometida que contaba con importantes avances económicos e industriales (Vásquez, 1990), lo cual ha dado paso a que este distrito sea visto como un sector que fue construido por fuera de la planeación de la ciudad, suscitando permanentemente discusiones para identificar y exigir acciones estatales orientadas a fortalecer factores como salud, educación, servicios públicos, infraestructura y seguridad, que son las principales carencias que la comunidad enfrenta desde entonces.

En este sentido, en los últimos años se vienen desarrollando obras que en cierta medida dan cuenta de formas de intervención para estas problemáticas. Por ejemplo, según la Encuesta de Percepción Ciudadana del programa Cali como Vamos (2019), la comunidad de Aguablanca, en los últimos diez años, ha aumentado favorablemente sus niveles de satisfacción respecto a los servicios de acueducto, energía, alcantarillado, malla vial y salud. Al mismo tiempo, el desarrollo e inauguración de ciudadelas educativas y la ejecución de programas promovidos por la Secretaría de Seguridad y la Secretaría de Paz y Cultura, como lo es "Gestores de Cultura Ciudadana" (Mera-Cobo, 2019), que ofrece alternativas de convivencia, educación y trabajo a jóvenes de Aguablanca, dan cuenta de que la educación del sector es una preocupación para las administraciones locales. Una de las principales preocupaciones tiene que ver con la alta tasa de homicidios que se registran anualmente en Cali, y que posicionan a la ciudad como una de las más peligrosas del mundo, pues registra tasas de muertes violentas por cada cien mil habitantes que superan las registradas en todo el país (Guzmán; Rodríguez; Muñoz, 2018); pero en los últimos años, especialmente en los períodos 2004-2008 y 2013-2018, según los datos del Observatorio de Seguridad de la Alcaldía de Santiago de Cali (2019), se ha disminuido considerablemente el número de muertes violentas, pasando de 2131 registros en 2004 a 1141 en 2018. 
Estas acciones pueden ser interpretadas como los resultados, aun incipientes pero relevantes, de un Estado donde salud, seguridad, educación y servicios públicos han sido propósitos de los últimos gobiernos. Dicho de otra forma, es el reflejo de un Estado que hace frente a las carencias de la comunidad. Pero la realidad es más compleja para los habitantes de Aguablanca, pues las realidades históricas bajo las cuales se han configurado cada uno de los espacios y comunidades que habitan y conforman el sector hacen que en este se reúna una gran cantidad de desventajas y vulnerabilidades que condicionan la cotidianidad de sus habitantes, ya que lo que se presenta son avances en infraestructura, salud y educación, pero en términos de violencia la realidad es otra. Por ejemplo, en la Figura 1 se puede observar la disminución de los homicidios registrados en la ciudad, al tiempo que permite identificar que históricamente el distrito de Aguablanca ha sido protagonista en estos registros porque en el período 2004-2018 fue el sector con mayor número de muertes violentas registradas.

\section{FIGURA 1 Homicidios por comuna (C)}

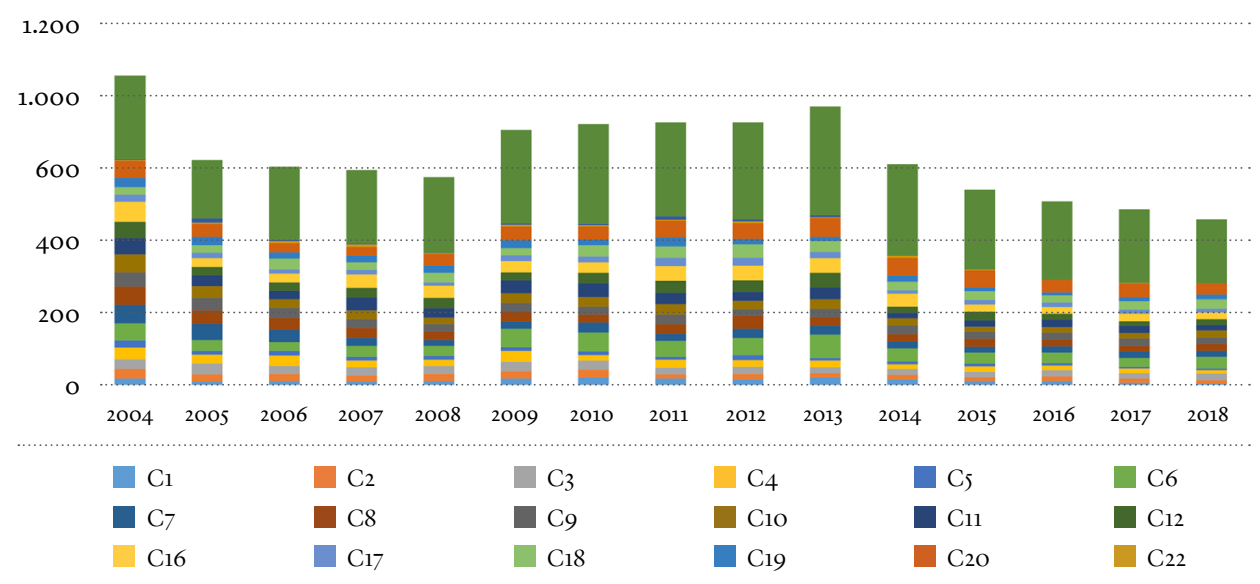

Fuente: elaboración propia a partir de los datos registrados por el Observatorio de Seguridad de Cali (Alcaldía de Santiago de Cali, 2019).

Vemos también que, mientras en 2004 el $26 \%$ del total de muertes eran registradas en Aguablanca, para el período 2014-2018 la representatividad fue superior al $40 \%$, mientras en otras comunas no se obtuvo registro alguno (C22). Es decir, las acciones enfocadas en disminuir las muertes violentas tienen efectos positivos en 
zonas privilegiadas de la ciudad, pero en el distrito de Aguablanca la disminución de este flagelo es mínimo y mantiene a este sector como una zona urbana donde la violencia y muerte hacen parte de su cotidianidad. Estamos bajo un panorama donde, a pesar de tener la posibilidad de rastrear algunas acciones estatales que se enfocan en este distrito y dan cuenta de su presencia, sus habitantes conviven permanentemente con la violencia y la muerte, lo cual con frecuencia es visto como un efecto de la ausencia del Estado. Esto muestra cómo la violencia interactúa con las nociones presencia y ausencia estatal, lo cual da paso a lecturas sociales y conflictos simbólicos donde se busca identificar y señalar a los responsables.

Surge entonces la necesidad de preguntarse cuáles son los efectos sobre la violencia urbana de las acciones y omisiones del Estado en Aguablanca, y cuáles los imaginarios que la comunidad, tanto del distrito como de otras zonas de la ciudad, construyen respecto a estos. Los imaginarios son aquí comprendidos como esquemas de representación que se construyen socialmente con injerencia de las imágenes que actores sociales generan respecto a una ciudad o una de sus partes, y a partir de los cuales se busca manifestar las formas deseables de legitimidad o legitimadoras en/ de un orden social para dar continuidad a la sociedad establecida, reproduciendo las formas y relaciones que regulan la vida de hombres y mujeres por medio de representaciones asociadas a supremacías raciales, de clase y género (Girola, 2012).

Por lo tanto, indagar sobre los efectos de la presencia y ausencia del Estado resulta importante porque es desde aquí que se están configurando imaginarios que mantienen al distrito de Aguablanca como un sector ampliamente vulnerado, pues para la comunidad las acciones del Estado son insuficientes, porque siguen siendo las familias del lugar las que aportan la mayoría de muertes en la ciudad, e improcedentes, porque niegan los procesos de autogestión comunitaria con formas de intervención que crean nuevos escenarios de conflicto y violencia.

En este sentido, para avanzar en la lectura sobre el papel del Estado en la violencia, se expondrán los efectos que tuvo el proyecto habitacional Torres de la Paz (Alcaldía de Santiago de Cali, 2018), desarrollado desde 2018 en Aguablanca, que apuntaba a generar más de mil soluciones de vivienda para familias que habitaban zonas de riesgo. Este proceso que al parecer favorecería un número importante de familias empobrecidas, dio paso a confrontaciones entre la comunidad y el Estado, porque, como lo expusieron madres y lideresas comunitarias, se estaban afectando los procesos comunitarios de autogestión y seguridad por la trasformación de los espacios que se utilizaban para procesos de (re)socialización con jóvenes, y porque se reubicaron grupos al margen ${ }^{2}$ que podían aumentar los conflictos territoriales con

2. Formas de organización armada como las pandillas, que operan en contextos de violencia urbana. No son llamados grupos al margen de la ley con el propósito de integrar el reconocimiento que estos 
grupos ya establecidos. Esto llevó a la comunidad a realizar plantones que fueron intervenidos por representantes del Estado, porque se señalaron como acciones enfocadas a la destrucción y suscitó la presencia de integrantes de la policía, Escuadrones Móviles Antidisturbios (ESMAD), Grupo de Operaciones Especiales (GOES) y cuerpo de carabineros (El País, 2017b).

Después, en uno de los encuentros con líderes y habitantes del distrito de Aguablanca que tenía como propósito gestionar alternativas para este proyecto habitacional, madres y lideresas expusieron que estas confrontaciones, además de estar enfocadas en neutralizar las peticiones de la comunidad, mostraban cómo en Aguablanca "el Estado se manifiesta con opresión mientras que las comunas están huérfanas de leyes". En este relato emerge una paradoja donde al mismo tiempo que se rechaza la acción de un estado opresor se pide su presencia (leyes). En esta paradoja, la presencia y ausencia del Estado no son fácilmente delimitables ni se pueden reducir a acciones que se visibilizan en infraestructura o indicadores, porque mientras la violencia sea protagonista en la comunidad o en las interacciones de esta con el Estado, su presencia o ausencia se reducirá a una noción que es utilizada desde diferentes sectores para dar una explicación a la realidad histórica del distrito. Por tanto, en este artículo se sostiene que la simultánea presencia y ausencia estatal son, a su vez, formas de comprensión y manifestación del Estado, y donde la efectividad para garantizar seguridad y disminuir la violencia que ofrezcan los grupos estatales o paraestatales, que son protagonistas en estas formas de representación, definirán sus límites y responsabilidad en la violencia urbana.

Esto ha generado un imaginario donde la ausencia o presencia del Estado no es un hecho material, ya que, mientras los habitantes de Aguablanca continúen siendo frecuentemente asesinados, toda acción resultará insuficiente o se convertirá en omisión cuando no redunde en la disminución de la violencia y homicidios. Estos efectos se encargan de configurar necesidades que traspasan las solventadas, pues aquí la violencia puede ser el resultado de la acción de un Estado que busca pagar una deuda histórica con un sector que no hizo parte de la planificación inicial de la ciudad, o el efecto de la emergencia de nuevos ordenes sociales ${ }^{3}$ donde son protagonistas grupos que transitan entre lo legítimo e ilegítimo (Vinasco-Martínez, 2019). Asimismo, cuando la ausencia y presencia estatal no son fácilmente delimitables y se relacionan directamente con la violencia, se crea un escenario donde se confrontan

obtienen en su relación con la comunidad de la zona en la cual operan, los cuales, según Alves (2O17), son considerados una forma de organización política.

3. Para Bobea (2017), el orden social es visto como el conjunto de normas que regulan la interacción entre los individuos de una comunidad donde se preestablecen normas que son compartidas, y cuenta con la injerencia de grupos o formas de organización legítima e ilegítima. 
imaginarios sociales involucrando a los habitantes del distrito, los de otras zonas de la ciudad y funcionarios estatales.

Serje (2012) y Ramírez (2001) analizaron las maneras como se configuran la presencia y ausencia del Estado en contextos de violencia, mostrando la necesidad de que este tipo de análisis incluya otros grupos sociales, empresariales, administrativos y políticos que tienen injerencia en la configuración y prácticas del Estado. Por lo tanto, analizar la violencia cuando la presencia y ausencia estatales se manifiestan simultáneamente implica alejarse de la idea de un Estado monolítico que actúa bajo la noción de legitimidad, y prestar especial atención a las acciones de los funcionarios que tienen como propósito administrar diferentes sectores de la ciudad. Es por esto que, en adelante, veremos cómo en contextos de violencia urbana las acciones de grupos que buscan/pueden tener injerencia en la configuración y decisiones del Estado tienen como propósito identificar a los responsables de la violencia con el fin de controlarla, para lo cual se exponen lecturas sociales donde, en este caso, por ser Aguablanca un sector mayoritariamente habitado por mujeres y hombres negros ${ }^{4}$, al tiempo que es el que más homicidios registra en la ciudad, se justifica la creación de identidades violentas y geografías de violencia racializada que suscitan acciones sociales y estatales nocivas para la comunidad de este distrito.

\section{Comunidad y violencia racializada}

Los numerosos homicidios registrados y la dificultad estatal para abordar esta problemática de manera efectiva y equilibrada favorecen la propagación de un imaginario que muestra al distrito de Aguablanca como el sector peligroso, como otro lugar que esta fuera de la ley y donde la muerte y el peligro son tanto cotidianidad como necesidad. Durante el proceso de investigación, al pedir a personas de la ciudad de Cali sus apreciaciones sobre este distrito, las respuestas se orientaron frecuentemente a advertir sobre los riesgos a los que se enfrenta aquel que se atreva a "entrar" al sector, donde lo mejor es desprenderse de todo objeto de valor para no correr riesgos y evitar que "allá le dan bala", pero si la insistencia es "entrar, pregúntele a los negros, ellos le darán una buena información porque son de allá”. Incluso el alcalde de Cali, Maurice Armitage (2016-2019), durante una entrevista en la cual pretendía

4. Según el Departamento Administrativo Nacional de Estadísticas (DANE, 2005), la población negra representaba el $26,2 \%$ de la población total de Cali. Cerca del $68 \%$ de esta comunidad está ubicada en alguna de las comunas del oriente o centro-oriente. Si bien el DANE actualizó el censo nacional en el año 2018, nos abstenemos de utilizar estas cifras debido al error -y señalado etnicidio- que dicha actualización generó y que borró cerca de 1,3 millones de personas negras y afrodescendientes del país. 
explicar la violencia entre hinchas de equipos de fútbol, describió a Cali como una ciudad "muy explosiva... donde tenemos un millón de negros que convivimos con ellos en paz, los queremos mucho, pero tenemos que tener cuidado sobre todo con este tipo de violencias" (Redacción Digital CM\&, 2017).

Estos relatos son una muestra de manifestaciones que permanentemente tienen lugar en múltiples escenarios y hacen uso de la categoría social de raza para explicar la realidad violenta del distrito de Aguablanca y la ciudad. Si bien la comunidad de Aguablanca reconoce que el sector enfrenta problemas de violencia, estas manifestaciones son nocivas porque, más que discutir los efectos de esta problemática, genera y utiliza la relación negritud-violencia para señalar a los individuos y espacios que son violentos y de los cuales se "debe tener cuidado". Por eso representar a Aguablanca como un sector al cual se "entra" y que, además, cuenta con habitantes racializados porque las comunidades negras "son de allá", muestra cómo en Cali operan patrones de división racial y territorial que definen quien(es) puede(n) identificarse como parte de la ciudad y cuáles son los espacios donde la violencia se debe/puede ejercer.

En este sentido, reconocer que la categoría de raza y la configuración de los espacios son protagonistas en la creación de imaginarios donde la racialización opera como una forma de control en contextos de violencia urbana (Cabrera, 2018) da cuenta de que, ante la dificultad de reducir el impacto de la violencia en Cali, los habitantes de zonas diferentes a Aguablanca han optado por señalar cuerpos y espacios que consideran culpables, exigiendo la ejecución de acciones contenciosas que impidan que estos problemas se expandan a otras zonas. De esta manera, la violencia opera dentro de un imaginario social que plantea que, mientras esta no traspase las fronteras que separan el distrito de Aguablanca del resto de Cali, la acción del Estado es evidente y satisfactoria, pero si el caso es contrario, su ausentismo sería protagonista más allá de que se mantenga a Aguablanca como un sector históricamente vulnerado.

Sumado a lo anterior, la relación negritud-violencia da paso a la ejecución de prácticas sociales donde el ejercicio de ciudadanía, es decir, la posibilidad de ser parte de las dinámicas propias de una ciudad se reduce y, en algunos casos, desparece para hombres y mujeres de Aguablanca que sienten cómo la ciudad los señala y asesina (Agamben, 1998; Das; Poole, 2008). Mujeres y hombres negros, al atravesar las avenidas Simón Bolívar y Ciudad de Cali, que separan a Aguablanca del resto de la ciudad, con propósitos laborales, educativos o de usufructo de los espacios, se encuentran con barreras raciales y territoriales donde, como lo describían las mujeres en uno de los talleres con el grupo juvenil, mencionar que se es habitante de Aguablanca evoca vulnerabilidades donde mujeres y hombres negros son dignos solo para recibir ofertas laborales enfocadas en la servidumbre o trabajos de construcción, pues 
la posibilidad de involucrarse con otro tipo de trabajos especialmente si requieren manejo de dinero son mínimas, porque se trata de hombres y mujeres a quienes les "toca andar con el bolso abierto para que vean que no nos estamos robando nada".

La falta de acciones efectivas para la solución de los problemas históricos vividos en Aguablanca y la relación violencia-negritud se encargan de desechar lo que puede significar el distrito y sus comunidades a nivel social. Hay un imaginario en el cual transitan rasgos que configuran la idea de un ciudadano de bien y toma distancia de aquello que no puede ser considerado como tal. Allí, ser negro y habitante de Aguablanca no es un elemento válido. Para Moreno (2013), y Moreno y Mornan (2015), se trata del racismo socialmente negado que evoca vulnerabilidades que impiden a madres y jóvenes vivir la ciudad, convirtiendo toda relación a la que logran acceder en una disputa donde se instrumentaliza su humanidad, y de la cual reciben cuidados paliativos que buscan mantener con vida al sector de donde proviene la mano de obra barata, pues "las mujeres de Aguablanca barren y limpian casas, y los hombres construyen centros comerciales que nunca podrán disfrutar porque no están hechos para una comunidad como la que habitamos el oriente".

Ahora bien, en las zonas urbanas con baja legitimidad estatal o dificultades para identificar las acciones concretas del Estado respecto a la violencia, la creatividad de la comunidad se convierte en estrategia para visibilizar y hacer frente a este tipo de problemáticas. En Aguablanca múltiples organizaciones como la Casa Cultural el Chontaduro, Colectivo Casa Amarilla, La Casa de la Mujer, Fundación Paz y Bien, Fundación para el Desarrollo y el Fomento del Bienestar Social y agrupaciones musicales y teatrales, han desarrollado, por más de tres décadas, estrategias sociales y culturales que buscan favorecer el bienestar de la comunidad que enfrenta los efectos de la violencia racializada. Para estas agrupaciones, violencia y negritud son también dos categorías centrales en las diferentes estrategias, pues de manera general buscan ofrecerles a hombres y mujeres del distrito oportunidades de formación cultural, educativa y laboral, y procesos de alfabetización que les permitan reconocer y hacer frente a los efectos de la violencia racializada.

En las diferentes estrategias, hombres y mujeres del distrito usan sus cuerpos, voces, letras, calles y demás medios que estén a su disposición para denunciar el efecto de las barreras raciales y territoriales; evocan memorias y experiencias vividas en calles y esquinas del distrito como una manera de dignificar la vida y muerte de amigos, vecinos y familiares, donde el diálogo y la escritura emergen como forma de denunciar que la muerte violenta se ha convertido en parte del paisaje. En una de las sesiones de trabajo realizadas con un grupo de aproximadamente veinte jóvenes negros/negras (entre los 14 y 24 años), se escribieron y socializaron más de una docena de cartas, cuentos, poemas y canciones que relataban la vida y muerte 
de algunos de sus amigos asesinados en las calles. Tras la socialización de las historias, se hizo evidente que las razones de los homicidios insinuaban la existencia de un patrón común de muerte donde estar en una esquina o calle del distrito, per se y como efecto de la violencia racializada, es razón suficiente para que un joven sea asesinado porque "está en el lugar equivocado", "con quien no debía”, "por precaución, porque si es negro es peligroso" o porque recoge las características de un sujeto violento (joven habitante de zona marginada) (Riaño, 2006).

Esto da cuenta de que los imaginarios sociales que señalan de una forma simplista a las comunidades del distrito de Aguablanca como responsables de la violencia y los males urbanos, representan también una forma de oposición a la organización y autonomía de las prácticas y estrategias que se utilizan para denunciar los efectos de la violencia urbana en zonas marginadas (Das; Poole, 2008; Ramírez, 2001). Mientras estos funjan como prescriptores de los rasgos de un ciudadano de bien $\mathrm{y}$ de la ciudad ideal, las prácticas y estrategias que desarrollen aquellos sujetos que no reúnan tales rasgos entrarán en disputas simbólicas por el significado que se les quiere asignar. En este caso, las prácticas sociales y estatales que homogeneizan un lugar y los cuerpos que lo habitan, al señalarlos como violentos por poseer unas características raciales y espaciales específicas, se vuelven decisorias sobre la vida de aquellos a los que "están matando poco a poco de maneras sutiles".

Estos imaginarios influyen tanto en la generación y ejecución de políticas de seguridad que operan bajo la idea de que el malo es el hombre negro o mujer negra habitante de Aguablanca (Alves, 2017; Alves; Moreno; Ramos, 2015) como en la circulación de narrativas sociales que justifican, normalizan y reclaman la intervención de fuerzas y violencias legítimas e ilegítimas que redunden en muertes y se traduzcan en seguridad para las demás zonas de la ciudad. Así lo describe un comerciante caleño:

lo que se necesita es que se haga una limpieza social. Desde que los negros llegaron se aumentaron los robos y las muertes, Cali antes no era así (...) se necesita es que caigan unos cuantos y ya todo mundo vive tranquilo. (Comerciante caleño, comunicación personal, 22.03.2019).

Este relato permite ver cómo en los imaginarios racializados la herencia de una ciudad próspera y cívica se vio afectada por las migraciones de comunidades negras a mediados del siglo XX, lo que ha hecho que se culpabilice a estos hombres y mujeres por un pasado y un presente que trasciende estas deducciones racistas, afectando la cotidianidad de comunidades y organizaciones que en Aguablanca buscan enfrentar estas señalizaciones y sus efectos. Como veremos a continuación, estos imaginarios, la ausencia-presencia del Estado y la violencia racializada favorecen la 
focalización de acciones que buscan controlar y coaccionar a los sujetos y espacios que se piensan como los responsables de la violencia urbana, pues es aquí donde la comunidad señala a policías y otros funcionarios estatales de actuar condicionados por el imaginario racializado, creando un concepto de seguridad que transciende la del Estado mismo y redunda en violencia.

\section{La intervención: entre el Estado y el funcionario}

En una de las discusiones sobre el proyecto habitacional Torres de la Paz, una lideresa comunitaria describió un enfrentamiento entre pandillas y policías que se dio durante las protestas. Para ella, el enfrentamiento resultaba admirable por la gestación de nuevas relaciones comunitarias:

es que vea, ¿sabe usted qué significa el hecho de que las pandillas paren los conflictos entre ellas y ataquen a los policías que nos estaban atacando? (...) Lo que usted veía era que las pandillas estaban unidas con la comunidad (...) los niños chiquitos corrían a traerles piedras a los grandes y las vecinas dejaban abiertas sus casas para refugiarse cuando la policía se nos venía encima. (Líder comunitaria, mesa de trabajo, 16.08.2018).

El relato muestra cómo en el distrito de Aguablanca las pandillas se constituyen como actores que, además de interactuar en las dinámicas de la violencia, son reconocidos como una forma de hacer frente a la misma, dando cuenta de que la configuración de órdenes sociales se relaciona tanto con las condiciones socioeconómicas (Vinasco-Martínez, 2019) como con la disputa por los procesos de autogestión y de seguridad comunitaria. Siguiendo a Alves (2019), la violencia indiscriminada que se ejerce sobre la comunidad del distrito de Aguablanca es la que ha forzado la generación de otras formas de territorialidad, comunidad y seguridad, que invitan a comprender la presencia y acción de las pandillas como formas localizadas de gobernanza y como una respuesta a los efectos del abandono del Estado.

Si bien el autor muestra cómo estas acciones se desarrollan en algunos barrios con el propósito de evitar que otras pandillas afecten la seguridad, el relato anterior nos invita a considerar que la presencia y acción de estas, en este caso como parte de confrontaciones entre la comunidad y el Estado, llegan incluso a redefinir dichas territorialidades con propósito de proteger a la comunidad de la acción violenta de la policía. Es decir, la manifestación del Estado como una fuerza represiva da paso a contiendas que le otorgan a las pandillas formas de reconocimiento más amplias y no necesariamente ligadas al desorden. Esta aceptación por parte de la comunidad muestra que la violencia como respuesta a la represión policial permite el fortale- 
cimiento y reconocimiento de grupos al margen, que tienen incluso la capacidad de regular el impacto sobre la comunidad para brindar seguridad en zonas donde la policía ha sido señalada de ser violenta, configurando escenarios que tienden a aumentar las conflictividades porque cada uno de los actores opera con un concepto propio de seguridad y justicia.

En este sentido, Alves (2019) también argumenta que las acciones de protección que desarrollan pandillas en ciudades de Latinoamérica con sectores violentos y marginados requieren de análisis más amplios sobre su función, especialmente cuando se dan como respuesta a un Estado violento. Es por esto que se hace necesario que el análisis del papel de las pandillas comprenda-y, en su posibilidad, trascienda-las descripciones que las señalan permanentemente como grupos al margen de la ley, pues, como hemos visto, la siniestra ausencia-presencia del Estado está dando paso a un escenario donde la búsqueda de protección para la comunidad lleva a redefinir las territorialidades para confrontar los conflictos que se generan entre la comunidad del distrito de Aguablanca y la policía.

Son estas conflictividades las que llevan a que las acciones de la policía sean consideradas como violentas, porque es aquí donde se materializan formas de ejercer seguridad que apelan contra las institucionales por su ineficiencia o debilidad para garantizarla; es decir, las ambigüedades que emergen de la presencia-ausencia estatal llevan incluso a sus funcionarios a rechazar las formas legítimas de seguridad y operar por medio de otras donde lo que se prioriza son sus imaginarios. Esto se puede ver representado en las palabras de un patrullero de la policía que laboró durante más de dos años en Aguablanca, y que dan cuenta de lo limitadas y confusas que pueden resultar las formas de operar cuando el Estado no puede ser simplemente reducido a nociones hegemónicas de legitimidad:

es que vea, a usted le dan la orden de que tiene que hacer cuadrante o lo trasladan para el distrito y usted ya sabe que allá es a otro precio (...), le dicen que lleve a la gente por la buena pero uno ya sabe cómo es eso allá, si no se va a la delantera pues ahí sí grave, entonces lo mejor es adelantarse, ir con la de uno y cuando usted pilla al negro ya sabe que puede ir armado o con droga, entonces toca cogerlo es de quieto para hacer puntos, m’hijo, para poder pedir traslado a otra zona. (Patrullero de la policía, comunicación personal, 04.02.2019).

Si bien resulta irresponsable asumir que estas formas de operar de la policía son parte de su institucionalidad, no se puede obviar que existen funcionarios en zonas marginadas que ingresan y salen fácilmente de lo legítimo, ya que, dada la propia interpretación que estos realizan sobre seguridad y violencia, por los efectos que la vida institucional puede acarrear para su integridad, se priorizan 
lecturas personales, porque estas resultan más eficaces para trabajar en contextos de violencia urbana. Esto permite que sus acciones y concepciones trasciendan las del Estado mismo, pues priorizan unas formas de vigilancia respecto a otras y optan por coaccionar a la comunidad como forma de orden. Esto tiene fuertes repercusiones porque en las ciudades con altos índices de violencia y que cuentan con imaginarios que señalan a una comunidad o espacio como responsables, con frecuencia se pide presencia, acción y aumento policial para reducir los índices de violencia, pero ¿cómo influye el hecho de que la violencia en Cali opere bajo patrones de racialización? Esto, indudablemente, invita a otorgar un lugar especial a los relatos de la comunidad que sufre los efectos de la violencia estatal, ya que, en Cali, a pesar de las denuncias ciudadanas, no se tienen datos oficiales sobre la violencia policial porque estos son aún una utopía.

Durante las visitas a Aguablanca se pudo notar que en una de sus esquinas se instaló un puesto de vigilancia conformado por cuatro policías, y respaldado por patrullas y motos que permanentemente rondaban el sector. Este puesto fue instalado como respuesta a las denuncias realizadas por parte de la comunidad sobre el aumento de robos e intimidaciones a algunos de los vecinos. Pero en uno de los talleres, mientras los jóvenes analizaban la seguridad del distrito, emergieron relatos de inconformismo con el papel que venían desempeñando estos policías. Los jóvenes argumentaron que "no cumplen con su labor, se la pasan mirando sus celulares y molestandos con las niñas del barrio"; incluso son reiterados los casos donde estos realizan requisas selectivas a jóvenes negros que señalan "porque tienen un aretico ${ }^{6}$ o porque están sentados en la esquina", mientras que en momentos donde se requiere de sus servicios para intervenir en algún acontecimiento relacionado con la violencia (riñas, hurtos u homicidios) "primero se muere uno antes de que la policía llegue". Uno de los jóvenes contó que al estar sentado fuera de su casa fue increpado por un policía que se refirió a él como un "negro asqueroso" antes de ordenarle que ingresara a la casa para evitarse problemas.

Si bien la presencia de la policía en el distrito de Aguablanca tiene que ver con los homicidios y las denuncias de la comunidad que encuentra seguridad en esta, el hecho de que sus acciones se centren en la vigilancia y hagan uso de imaginarios racializados para anteceder supuestos focos de violencia aumenta la desconfianza que las comunidades tienen hacia esta institución. El aumento permanente en el

5. Hacen referencia a conversaciones que en ocasiones buscan cercanías sentimentales o sexuales.

6. Arete o aro de metal que se utiliza en el lóbulo de la oreja. 
número de efectivos de la policía ${ }^{7}$, que favorece la burocratización de esta institución (Guzmán, 2013; Guzmán; Rodríguez; Muñoz, 2018), les brinda a sus funcionarios la opción de centrarse en aumentar la percepción de seguridad sin importar los medios de consecución y sus efectos. $Y$ aunque, efectivamente, estas tasas disminuyen, no se puede asumir que se deba explícitamente a la acción policial, pues resulta importante reconocer que por las acciones de grupos al margen y la desconfianza que a la comunidad le generan las acciones de la policía, se desarrollan permanentemente estrategias que acarrean beneficios en términos de seguridad, como lo es no salir de las casas o desplazarse a otras regiones/comunas.

Por eso es importante analizar la relación que la policía entabla con la comunidad de zonas urbanas marginadas, especialmente donde la constante intimidación permite legitimar el accionar violento en los casos que consideran amenazantes y además convierte la violencia en un rasgo atribuible a los hombres y mujeres habitantes de estas zonas (Saborio, 2017). En Cali, la seguridad se ha entendido, por antonomasia, como el aumento de operativos en el oriente de la ciudad, lo cual da cuenta de la identificación del espacio como foco de inseguridad y violencia donde lo importante es que se "controle a los negros responsables de los problemas de la ciudad". Las denuncias de la comunidad que quieren mostrar la existencia de patrones de violencia policial se enfrentan con imaginarios que plantean que la baja tolerancia al fracaso, el empoderamiento mental que genera el uso del uniforme, el miedo del funcionario y creencias con las que crecen los policías son los detonantes de sus intervenciones excesivas, que por ser responsabilidad del o la funcionaria no son atribuibles a la institución, lo que favorece la invisibilización de la violencia policial con eufemismos como uso excesivo de la fuerza (Salazar; Paniagua; Contreras; Mejía; Restrepo, 2018).

Esta problemática se extiende a lo largo de otras ciudades latinoamericanas como São Paulo (Brasil), donde la intervención policial y estatal es violenta cuando actúa sobre las comunidades negras de zonas marginadas y empobrecidas (Alves, 2014; González, 2017). Esto exige que, para mostrar los diferentes lugares que en esta problemática ocupan los cuerpos racializados que viven en Aguablanca, cuando se nombre la violencia a nivel social y en investigaciones sea de una manera no reduccionista, responsabilizando de los índices de violencia solo a pandillas, fronteras invisibles y microtráfico, o donde ser negro o negra sea solo una referencia descriptiva y de acercamiento etnográfico (Lasso, 2013; Ordoñez, 2016; Quintín; Urrea, 2001), pues urge poner especial atención a la forma como los funcionarios del Estado, especialmente la policía, enfocan sus acciones violentas en grupos racializados, por

7. A enero de 2018, Cali es la tercera ciudad con mayor número de policías (8000 aprox.), después de Bogotá (20 ooo aprox.) y Medellín (9000 aprox.) (RedMas, 2018). 
la flexibilidad de sus obligaciones y el alto nivel de legitimidad que se les otorga tras breves períodos de formación.

En relación con lo anterior, resulta innegable que el ejercicio policial esta permeado por el imaginario racializado que circula en Cali, pues además de los relatos donde se evidencia que la negritud se convierte de nuevo en una referencia para la violencia, se da paso al desarrollo de estrategias que buscan contener a la comunidad, anticipando las acciones en las que se verán involucrados los lugares y cuerpos de mujeres y hombres negros. Es por eso que, en el imaginario de los policías, un lugar o acción que dé paso a la reunión o aglomeración de hombres y mujeres del distrito de Aguablanca se convierte en una señal de alerta que debe ser inmediatamente vigilada o intervenida. En los talleres, una de las lideresas juveniles describió una de las prácticas comunitarias que se realizan en Aguablanca, el Carnaval de la Luz, el cual es

una de esas tantas formas de resistencia para devolver la esperanza a nuestros territorios, que consiste en que diferentes organizaciones y fundaciones de Aguablanca convocan y se movilizan para hacer recorridos por calles y esquinas para, con actos simbólicos, como encender velas o portar prendas de vestir con fotos estampadas de los jóvenes asesinados, resignificar la vida de quienes han muerto. (Líder juvenil, taller juvenil, 18.11.2017).

Sin embargo, los imaginarios que emergen de la relación negritud-violencia hacen que este tipo de prácticas sean vaciadas de contenido con discursos y formas de exclusión y de señalamiento que pretenden representar lo que es el sector. Durante este trabajo fue posible evidenciar cómo las calles y esquinas que se iluminan con velas y se ambientan con representaciones culturales como manera de recuperar el espacio eran permanentemente señaladas con grandes estelas de luz que provenían del helicóptero Bell 407 operado por la policía (El País, 2017a), que si bien fue presentado como propuesta de vigilancia para la ciudad, su operación es significativamente mayor en Aguablanca, por lo cual los jóvenes y madres tuvieron que ver cómo las estrategias y parte de su cotidianidad (reuniones y parches en las esquinas del barrio) se convertían en razones suficientes para que los pilotos (policías) los señalaran como focos de peligro con el propósito de tomar registro fotográfico de quienes estuvieran allí y de lo que estaban haciendo. Esta forma de intervención muestra cómo en Cali se opera con un enfoque racial que prioriza el control sobre el territorio, creando mapas de anticipación que le permiten al Estado hacer control de los espacios, con propósito de que esta sea una ciudad segura para los ciudadanos de bien e insegura para aquellos que no son considerados parte de ella (Jeganathan, 2018).

Sumado a esto, en Cali parecieran existir lógicas donde todo sujeto o comunidad que se considere ajeno a los propósitos sociales, económicos y políticos de la ciudad 
es borrado. Una de las madres del distrito narró cómo su hijo fue asesinado por un disparo que detonó un integrante de la policía mientras se encontraba en el sepelio de uno de sus amigos que había sido asesinado. La comunidad cuenta que en el momento que se realizó el disparo no había razón alguna para hacerlo, porque los jóvenes solo estaban acompañando a su amigo. Para esta madre, el asesinato de su hijo se convirtió en una muerte y tortura permanente, porque la posibilidad de reclamar y hacer justicia se encontraba a diario con una estructura burocrática donde cada opción de reclamo por la vida de su hijo se frenaba "porque faltó un papel", mostrando cómo la muerte de un joven negro en acciones de violencia policial o estatal parece no ser una posibilidad, pues el que muere es un negro del distrito que en el imaginario social, per se, era violento y peligroso.

Las familias son permanentemente torturadas por la gestión de un Estado ante el cual sus hijos o parientes mueren dos veces, pues sus reclamos y peticiones no son escuchadas, y no existe la posibilidad de hacer justicia (Aranguren, 2016). “¿A quién le duele[n] nuestros muertos?" es la pregunta que, durante encuentros, talleres o en los momentos que debe velar a sus hijos, sobrinos o vecinos, se hace la comunidad como una forma de reclamar por la apatía social y estatal que encuentran cada vez que uno de ellos es asesinado en las calles o discriminado en la ciudad. Esto se inscribe en el modelo protagónico de las ciudades de Latinoamérica, donde las comunidades negras de las zonas urbanas empobrecidas afrontan gran parte de los efectos de la violencia que emerge de la ausencia y presencia estatal, y donde la condición racial como elemento ajeno a su gestión aprueba un exterminio programado (Gómez; De Aguiar, 2015; Saad-Diniz; Boudoux, 2018).

La situación anterior está relacionada con el efecto de legibilidad producido por el Estado a partir de la documentación que materializa la idea de un sujeto, lo cual se constituye en un lenguaje y conocimiento para gobernar, regular y clasificar a las colectividades, favoreciendo el desarrollo de estrategias biopolíticas donde la etnicidad falla como forma de acceder a las membresías de inclusión ciudadana. Hemos visto que se juzgan algunas vidas sin valor y se crean cuerpos asesinables en aquellas personas que son excluidas de las comunidades políticas, por lo cual la mera sospecha, que reemplaza la ley y su aplicación, se convierte en razón suficiente para matar (Agamben, 1998; Foucault, 1979; Scott, 1998; Trouillot, 2001).

En este sentido, se argumenta que el Estado, visto desde las acciones de sus funcionarios e instituciones, hace uso de la violencia y los imaginarios racializados para desarrollar procesos y políticas de seguridad que, al definir quiénes son los buenos y malos ciudadanos por medio de rasgos como el color de la piel y sus lugares de residencia, etiquetan como permanentes sospechosos de la violencia en la ciudad a los habitantes del distrito de Aguablanca. Es decir, los imaginarios sociales racializados 
niegan a los habitantes de este sector toda posibilidad de ser vistos como parte de la ciudad, con posibilidades de participación e injerencia política, al tiempo que los sitúa en un estado de excepción donde las políticas de seguridad están enfocadas en contener a los enemigos del orden sin importar los medios.

Siguiendo a Civico (2012) y Mora (2013), al igual que en zonas urbanas de algunas ciudades como Brasil y México, los imaginarios racializados e indianizados son responsables de situar al margen del orden político a los y las habitantes de zonas urbanas marginadas y empobrecidas, ubicándolos en escenarios donde no es clara la distinción entre lo legítimo y lo ilegítimo, y se pierden los límites de la protección con propósito de perpetuar lógicas de seguridad estatal donde los sospechosos son fácilmente identificables. Es por eso que la comunidad del distrito de Aguablanca es permanentemente invisibilizada y desprotegida, porque son cuerpos que, en los imaginarios racializados, son vistos como sujetos que recogen las características sociales y económicas de los criminales y son susceptibles de reproducir el crimen y la violencia, lo cual da paso a que sean vistos como cuerpos asesinables, que deben ser contenidos o abandonados para evitar que sus males se extiendan a zonas urbanas privilegiadas.

En este sentido, la presencia-ausencia del Estado sirve como una tecnología de administración que, por un lado, despliega prácticas que contienen a los violentos y peligrosos, mientras, por otro, se abandona a los sujetos y territorios que son vistos como posibles lugares de reproducción de la pobreza y el crimen, generando una lógica donde los marginados y empobrecidos son vistos, a nivel social y estatal, como victimarios y necesarias víctimas de la violencia.

\section{Conclusiones}

Cali es considerada una de las ciudades más violentas del país y del mundo debido al alto número de muertes violentas que registra año tras año. Debido a esto, la seguridad se ha convertido en uno de los principales pilares de las administraciones locales que señalan al microtráfico, pandillas y fronteras invisibles como principales responsables de tan deshonroso reconocimiento. Sin embargo, se ha mostrado cómo, a pesar de las acciones estatales y sociales que han ayudado a disminuir el número de homicidios, este sigue siendo uno de los principales problemas en el distrito de Aguablanca que, además, genera confrontaciones entre los ciudadanos de zonas urbanas marginadas, los habitantes de otras zonas de la ciudad y el Estado, debido a que, tras la permanente búsqueda de alternativas para controlar este delito, la exigencia de acciones que confronten esta problemática lleva a hacer uso 
de imaginarios y lecturas reduccionistas que señalan al distrito de Aguablanca como el culpable de esta realidad.

En este sentido, las acciones que se realizan están perjudicando de manera directa a la comunidad de Aguablanca, porque en Cali hay imaginarios sociales y estatales que están creando relaciones directas entre violencia y negritud, debido a que en el distrito habita un número importante de mujeres y hombres negros migrantes del Pacífico, lo cual ha suscitado la creación de un mapa urbano que racializa la violencia y, por ende, señala al habitante negro de Aguablanca como responsable de la imagen deshonrosa que tiene la ciudad. De esta forma, la confrontación de la violencia se convierte en la ejecución de acciones que eviten que los cuerpos y lugares criminalizados se expandan a otras zonas, configurando prácticas de segregación que limitan el derecho a la ciudad de los habitantes de Aguablanca y convierte el sector en otro lugar u otra ciudad donde la muerte violenta se puede manifestar sin mayor conmoción social.

Al mismo tiempo, la realidad violenta de Cali ha favorecido la emergencia de discursos que aducen que la capacidad del Estado para hacer frente a las problemáticas relacionadas con la violencia es aún insuficiente, especialmente si se registra en zonas diferentes al distrito. Estos discursos no solo transitan en escenarios sociales, pues también permean a funcionarios del Estado y favorecen el rechazo de las nociones de control y seguridad con las que este opera, las cuales son reemplazadas por lecturas propias de lo que estos elementos deberían significar en un contexto de violencia urbana. Así, se crean escenarios donde se pueden ejercer prácticas que transitan fácilmente entre el castigo legal y extralegal, y donde la relación negritud-violencia es influyente, ya que la violencia policial que es presentada desde el eufemismo de uso excesivo de la fuerza asigna identidades violentas a jóvenes negros habitantes de Aguablanca.

Lo anterior tiene que ver con la configuración de un escenario donde la violencia da paso a imaginarios sociales y estatales que la reproducen, y donde la ausencia y presencia del Estado son particularmente protagonistas, no tanto por lo que pueda significar en sentido estricto cada noción, sino por los efectos de su manifestación simultánea. Dicho de otra manera, en la configuración de Aguablanca, la autogestión comunitaria ha sido la respuesta a la planificación de una ciudad donde este sector no fue considerado; desde entonces, la idea de que el sector está abandonado por el Estado aparece con frecuencia en manifestaciones sociales e incluso académicas, pero al mismo tiempo hay elementos que dan cuenta de la acción estatal y la satisfacción de la comunidad respecto al cubrimiento de algunos servicios. Sin embargo, mientras en las dinámicas de la violencia siga siendo Aguablanca el sector con mayor número de muertes en la ciudad y sus habitantes continúen siendo señalados, las 
acciones del Estado resultarán insuficientes y darán paso a lecturas donde su ausencia favorezca el aumento de los índices de homicidios con repercusiones en la ciudad, pero su presencia, especialmente la policial, tienda a ser violenta porque opera con conceptos propios de seguridad y desconoce los procesos de autogestión comunitaria.

Al mismo tiempo, la presencia violenta del Estado hace que parte de la comunidad opte por aceptar dinámicas de pandillas, que son vistas como manifestaciones políticas que configuran órdenes sociales donde la violencia es tanto un medio como un efecto. Dicha aceptación invita a redefinir las lecturas que señalan a las pandillas como grupos únicamente criminales, pues se ha podido evidenciar que estas tienen la capacidad de transformar sus prácticas y territorialidades con propósito de enfrentar el abuso estatal y policial en los sectores urbanos marginados. Se invita entonces a leer las acciones de las pandillas y el reconocimiento que los habitantes les otorgan como una forma de gestión política de la comunidad, por medio de la cual se da paso a las prácticas que se niegan a ceder ante los imaginarios que pretenden vaciar de contenido y asesinar cuerpos y territorios que no han sido reconocidos en la construcción simbólica de la ciudad y donde el Estado es cómplice de un exterminio programado sobre las comunidades racializadas.

Finalmente, las ideas aquí expuestas son una invitación a que las investigaciones que se realicen sobre violencia urbana tengan en cuenta la categoría social de raza como detonante de violencia policial, y no solo como una categoría de referencia. Investigar los mecanismos, tecnologías y efectos de la violencia policial en Cali es urgente para poder avanzar en la comprensión del fenómeno mismo, en contraposición a la idea de que un mayor número de policías garantiza seguridad o que su formación institucional es sin duda funcional. Además, resulta importante continuar indagando los efectos de la manifestación simultánea de las nociones de ausencia y presencia del Estado en ciudades con altos índices de violencia urbana, pues esta simultaneidad se erige como una tecnología de operación estatal que hace parte de un orden social donde los imaginarios que las comunidades tienen respecto a lo que el Estado debe realizar o a los efectos de sus omisiones están condicionados por las ventajas o desventajas que les ofrecen su condición racial y ubicación espacial. 


\section{Referencias}

Agamben, Giorgio (1998). Homo Sacer: Sovereign Power and Bare Life. Standford: Standford University Press.

Alcaldía de Santiago de Cali (3 de abril de 2018). Inicia construcción de proyecto habitacional Torres dela Paz. Recuperado de https://www.cali.gov.co/gestiondelriesgo/publicaciones/140104/ inicia-construccion-de-proyecto-habitacional-torres-de-la-paz/

Alcaldía de Santiago de Cali (2019). Informes Anual Homicidios. Recuperado de https://www. cali.gov.co/documentos/1201/informes-anual-homicidios/

Alves, Jaime (2014). From Necropolis to Blackpolis: Necropolitical Governance and Black Spatial Praxis in São Paulo, Brazil. Antipode, 46(2), 323-339. https://doi.org/10.1111/anti.12055

Alves, Jaime (2017). Gubernamentalidad espacial y agencia criminal negra en Cali y Sao Paulo: aproximaciones para una antropología "fuera de la ley". En Territorios y sociabilidades violentas: Santo Domingo, San Juan, Sao Paulo, Cali y Medellín (pp. 15-64), coordinado por Jorge Giraldo. Medellín: Universidad Eafit.

Alves, Jaime (2019). Refusing to be Governed: Urban Policing, Gang Violence, and the Politics of Evilness in an Afro-Colombian Shantytown. PoLAR, 42(1), 21-36. https://doi.org/10.1111/ plar.12276

Alves, Jaime; Moreno, Vicenta; Ramos, Brenda (2015). Notas preliminares para un análisis interseccional de la violencia en el Distrito de Aguablanca (Cali-Colombia). Series de Documentos de Trabajo del CIES, 5, 4-21.

Aranguren, Juan (2016). Cuerpos al límite: tortura, subjetividad y memoria en Colombia (19771982). Bogotá: Uniandes.

Bobea, Lilian (2017). Ganando terreno: orígenes y fundamentos de los ecosistemas transgresores en San Juan, Puerto Rico. En Territoriosy sociabilidades violentas: Santo Domingo, San Juan, Sao Paulo, Caliy Medellín (pp. 65-138), coordinado por Jorge Giraldo. Medellín: Universidad Eafit.

Cabrera, Nicolás (2018). Violencia, estigma y desplazamientos: la reconfiguración social y moral de Los Piratas en clave procesual.Antípoda, 30, 129-15o. https://dx.doi.org/10.7440/ antipoda30.2018.07

Cali cómo Vamos (2019). Encuesta de percepción ciudadana Cali 2019. Recuperado de https:// e6a9d32d-3a33-462e-9c91-cd6ao4132224.filesusr.com/ugd/ba6905_8d7be3c38e374621abf1042bbbeogee5.pdf

Civico, Aldo (2012). "We are Illegal, but not Illegitimate". Modes of Policing in Medellin, Colombia. PoLAR, 35(1), 77-93. https://doi.org/10.1111/j.1555-2934.2012.0118o.x 
Departamento Administrativo Nacional de Estadística (2005). Censo General 2005. Recuperado de: https://www.dane.gov.co/files/censos/libroCenso20o5nacional.pdf

Das, Veena; Poole, Deborah (2008). El Estado y sus márgenes: etnografías comparadas. Cuadernos de antropología social, 27, 19-52.

El País (27 de junio de 2017a). Ya está en Cali el helicóptero Bell 407 que vigilará la ciudad. El País. Recuperado de https://www.elpais.com.co/judicial/ya-esta-en-el-helicoptero-bell407-que-vigilara-la-ciudad.html

El País (24 de noviembre de 2017b). Controlan disturbios en el barrio La Paz, en el oriente de Cali, tras protesta contra urbanización. El Pais. Recuperado de https://www.elpais.com. co/cali/controlan-disturbios-en-el-barrio-la-paz-en-el-oriente-de-tras-protesta-contraurbanizacion.html

Foucault, Michel (1979). Governamentality, Ideology and Consciousness. Cambridge: Cambridge University Press.

Girola, Lidia (2012). Representaciones e imaginarios sociales. Tendencias recientes en la investigación. En Tratado de metodología de las ciencias sociales: perspectivas actuales (pp. 402-431), coordinado por Enrique de la Garza; Gustavo Leyva. México: FCE.

Gómez, Javier; De Aguiar, Rafael (2015). El imaginario urbano del miedo en Latinoamérica: evidencias de estudios en Salvador de Bahía, Brasil, y Monterrey, México. Temas Sociológicos, 19, 41-69.

González, Yanilda (2017). "What Citizens can See of the State": Police and the Construction of Democratic Citizenship in Latin America. Theoretical Criminology, 21(4), 494-511. https:// doi.org/10.1177/1362480617724826

Guzmán, Álvaro (2013). Seguridad ciudadana y seguridad del Estado. En Nuevo pensamiento sobre la seguridad en América Latina: hacia la seguridad como valor democrático (pp. 19-41), editado por Alexandra Abello-Colak; Pablo Emilio Angarita. Medellín: CLACSO.

Guzmán, Álvaro; Rodríguez, Alba; Muñoz, Nathalia (2018). Cali y la violencia paramafiosa. En Violencia en cinco ciudades colombianas, a finales del siglo XX y principios del siglo XXI (pp. 623-805), editado por Álvaro Guzmán. Cali: Universidad Autónoma de Occidente.

Jeganathan, Pradeep (2018). Border, Checkpoint, Bodies. En Routledge Handbook of Asian Borderlands (pp. 403-410), editado por Alexander Horstmann; Martin Saxer; Alessandro Rippa. London: Routledge.

Lasso, Patricia (2013). Cuando se vive el desarraigo. Educación y desplazamiento forzado: una mirada desde el Distrito de Aguablanca, Cali, Colombia. Revista Guillermo de Ockham, 11(2), 35-51. https://doi.org/10.21500/22563202.608 
Mera-Cobo, Alda Livey (30 de junio de 2019). De la violencia a 'gestores' de paz, la historia de estos jóvenes del Distrito, en Cali. El País. Recuperado de https://www.elpais.com.co/ judicial/de-la-violencia-a-gestores-de-paz-la-historia-de-estos-jovenes-del-distrito-encali.html

Mora, Mariana (2013). La criminalización de la pobreza y los efectos estatales de la seguridad neoliberal: reflexiones desde la Montaña, Guerrero. Revista de Estudos e Pesquisas sobre as Américas, 7(2), 174-208. https://doi.org/10.21057/repam.v7i2.10027

Moreno, Vicenta (2013). 'Ay dios baja y ve cómo las mujeres afrocolombianas resisten al destierro'. Revista CS, 12, 415-434.

Moreno, Vicenta; Mornan, Debaye (2015). ¿Y el derecho a la ciudad? Aproximaciones sobre el racismo, la dominación patriarcal y estrategias feministas de resistencia en Cali, Colombia. Revista CS, 16, 89-110.

Ordoñez, Jorge (2016). De la pandilla a la banda. Transformaciones de la violencia pandillera en barrios marginales en Cali. Sociedad y Economía, 32, 107-126.

Quintín, Pedro; Urrea, Fernando (2001). Ser hombre negro y joven: construcción de identidades masculinas entre sectores populares excluidos en Cali (Colombia). En Exclusión socialy construcción de lo público en Colombia (pp. 159-195), editado por Alberto Valencia. Bogotá: CEREC.

Ramírez, María (2001). Entre el Estado y la guerrilla: identidad y ciudadanía en el movimiento de los campesinos cocaleros del Putumayo. Bogotá: ICAH.

RedMas, Noticias (26 de enero de 2018). Colombia sigue teniendo un déficit en el número de policías [Archivo de video]. Recuperado de: https://www.youtube.com/watch?v=X_ JyHKVFSfo

Redacción Digital CM\& (22 de agosto de 2017). "Cali es una ciudad muy explosiva, tenemos un millón de negros": Armitage. Canal 1. Recuperado de https://noticias.canal1.com.co/ noticias/cali-es-una-ciudad-explosiva-tenemos-un-millon-de-negros-armitage/

Riaño, Pilar (2006). Jóvenes, memoria y violencia en Medellín: una antropología del recuerdo y el olvido. Medellín: Universidad de Antioquia.

Saad-Diniz, Eduardo; Boudoux, Amanda (2018). Violencia y victimización como costos sociales de la pobreza y de la desigualdad en Latinoamérica. Revista de Victimología, 7, 47-76.

Saborio, Sebastian (2017). Policía Pacificadora, legitimidad y prácticas de ocupación territorial. Antípoda, 29, 105-122. https://dx.doi.org/10.7440/antipoda29.2017.05

Salazar, Marisol; Paniagua, William; Contreras, Jorge; Mejía, Sandra; Restrepo, Emerson (2018). Uso de la fuerza policial: ¿efectividad o abuso? Revista In Vestigium Ire, 1(11), 109-138. 
Scott, James (1998). Seeing Like a State: How Certain Schemes to Improve the Human Condition Have Failed. New Haven: Yale University Press.

Serje, Margarita (2012). El mito de la ausencia del Estado: la incorporación económica de las “zonas de frontera" en Colombia. Cahiers des Amériques Latines, 71, 95-117. https://doi. org/10.400o/cal.2679

Trouillot, Michel-Rolph (2001). The Anthropology of the State in the Age of Globalization: Close Encounters of the Deceptive Kind. Current Anthropology, 42(1), 125-138.

Vásquez, Édgar (1990). Historia del desarrollo económico y urbano en Cali. Boletín socioeconómico, 20, 1-28.

Vinasco-Martínez, Diana (2019). Pacificando el barrio: orden social, microtráfico y tercerización de la violencia en un barrio del distrito de Aguablanca (Cali, Colombia). Cultura y Droga, 24(27), 157-187. https://doi.org/10.17151/culdr.2019.24.27.8 